Check for updates

Cite this: RSC Adv., 2017, 7, 20754

\title{
Site-selective biotransformation of ursane triterpenes by Streptomyces griseus ATCC $13273 \uparrow$
}

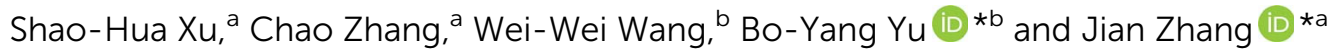

The oxidization of unactivated $\mathrm{C}-\mathrm{H}$ bonds of pentacyclic triterpenes (PTs) is of great interest for the structural modification of PTs. Herein, we discovered the unique capability of Streptomyces griseus ATCC 13273 to catalyze the site-selective oxidation of the C-30 methyl group to the carboxyl group and hydroxylation of the C-24 methyl group over a range of ursane triterpenes, including ursolic acid (1), 3oxo ursolic acid (2), and corosolic acid (3). It is noteworthy that while using asiatic acid (4) and madasiatic acid (5), which bear one hydroxyl group on C-23 as substrates, the hydroxylation on C-24 was blocked. As a result, eight new compounds ( $1 a-3 a, 5 a, 1 b-3 b$ and $5 b)$ of the metabolites were isolated and their structures were elucidated based on 1D and 2D NMR and HR-MS data. In addition, the cytotoxicity of substrates and transformed products was preliminarily evaluated by an MTT assay.

Received 13th February 2017 Accepted 29th March 2017

DOI: 10.1039/c7ra01811h

rsc.li/rsc-advances high added-value natural compounds or new natural productlike compounds. ${ }^{20-22}$

In our previous studies, some novel microbial transformations of pentacyclic triterpenoids such as asymmetric ketone hydroxylation ${ }^{23}$ and methyl hydroxylation ${ }^{24}$ have been reported individually. Streptomyces griseus ATCC 13273 has been proven as a potent strain that can achieve oxygenation of unactivated $\mathrm{C}-\mathrm{H}$ bonds of the olean-type pentacyclic triterpenes..$^{24}$ In order to investigate the regioselective oxidizing capability of S. griseus ATCC 13273 to ursane triterpenes and expand the structural diversities of PTs, five ursane triterpenes, ursolic acid (1), 3-oxo ursolic acid (2), corosolic acid (3), asiatic acid (4) and madasiatic acid (5), were used as the substrates in this study, resulting in eight new metabolites and one known metabolite. This was the first time the biotransformation of ursane triterpenes by S. griseus ATCC 13273 was screened. Moreover, the influence of the hydroxyl substitutions on the A and $\mathrm{B}$ rings on the reactions was also analyzed as the five ursane-type substrates bear different numbers of hydroxyl groups on the A and B ring skeleton: 3-oxo ursolic acid (2, with no hydroxyl group), ursolic acid (1, with one hydroxyl group at C-3), corosolic acid (3, with two hydroxyl groups at C-3 and C-2), asiatic acid (4, with three hydroxyl groups at C-3, C-2 and C-23) and madasiatic acid (5, with four hydroxyl groups at C-3, C-2, C23 and C-6). In addition, the cytotoxicity of the substrates and metabolites against HepG2 and MCF-7 cells was evaluated by an MTT assay.

\section{Results and discussion}

\section{Identification of transformed products}

Ursolic acid (1) (150 mg) was added into a 2 day-old culture of S. griseus ATCC 13273, and two additional polar metabolites, 
compounds 1a (48.6 mg, yield 30.4\%) and 1b (52.1 mg, yield $31.6 \%$ ), were isolated (Fig. 1).

Compound 1a was isolated as a colorless powder, and the HR-ESI-MS of compound 1a showed an $[\mathrm{M}-\mathrm{H}]^{-}$ion at $\mathrm{m} / \mathrm{z}$ 485.3260 (calcd for $\mathrm{C}_{30} \mathrm{H}_{45} \mathrm{O}_{5}, 485.3272$ ), indicating a $30 \mathrm{amu}$ mass increase compared to that of compound 1. The ${ }^{1} \mathrm{H}$ NMR spectrum of compound 1a displayed six characteristic methyl groups at $\delta_{\mathrm{H}} 0.94(3 \mathrm{H}, \mathrm{s}), 1.05(3 \mathrm{H}, \mathrm{s}), 1.09(3 \mathrm{H}, \mathrm{s}), 1.26(3 \mathrm{H}, \mathrm{s})$, $1.31(3 \mathrm{H}, \mathrm{d})$ and $1.32(3 \mathrm{H}, \mathrm{s})$, with the absence of one splitting methyl signal in the substrate. The ${ }^{13} \mathrm{C}$ NMR spectrum exhibited a new signal at $\delta_{\mathrm{C}} 179.02 \mathrm{ppm}$, and only six characteristic methyl signals appeared at $\delta_{\mathrm{C}} 29.25,24.48,19.43,17.90,17.04$ and $16.14 \mathrm{ppm}$. This evidence suggested that one methyl group might be oxidized to carboxyl group. Namely, the resonance of C-30 (a methyl group at $\delta_{\mathrm{C}} 21.41$ in ursolic acid) disappeared, and the carbon signal at $\delta_{\mathrm{C}} 17.52 \mathrm{ppm}$ attributed to C-29 shifted down-field $1.91 \mathrm{ppm}$ to $\delta_{\mathrm{C}} 19.43 \mathrm{ppm}$ in 1a, indicating that the oxidization was on $\mathrm{C}-30$. In addition, the three-bond correlation between $\delta_{\mathrm{H}} 1.31(\mathrm{~d}, 3 \mathrm{H}, \mathrm{H}-29) \mathrm{ppm}$ and $\delta_{\mathrm{C}} 53.10 \mathrm{ppm}(\mathrm{C}-20)$ was also observed in the HMBC spectrum. The relative stereochemistry of the carboxyl group was established as equatorial based on NOESY experiments. The NOESY spectrum of 1a showed NOE enhancements between $\delta_{\mathrm{H}} 1.31(\mathrm{~d}, 3 \mathrm{H}, \mathrm{H}-29)$ and $\delta_{\mathrm{H}} 2.80(\mathrm{~d}, 1 \mathrm{H}, J=11.4 \mathrm{~Hz}, \beta-\mathrm{H}-18) \mathrm{ppm}$. This further evidenced that the methyl group of $\mathrm{C}-30$ was oxidized to a carboxyl group in the biotransformation. Thus, compound 1a was elucidated as 3 $\beta$-hydroxy-urs-12-en-28,30-dioic acid, which is a new compound.

Compound 1b was isolated as a colorless powder, and the HR-ESI-MS of compound $\mathbf{1 b}$ showed an $[\mathrm{M}-\mathrm{H}]^{-}$ion at $\mathrm{m} / \mathrm{z}$ 501.3222 (calcd for $\mathrm{C}_{30} \mathrm{H}_{45} \mathrm{O}_{6}, 501.3222$ ), which indicated an increment of $46 \mathrm{amu}$ as compared to compound 1. The new signal at $\delta_{\mathrm{C}} 179.02 \mathrm{ppm}$ in the ${ }^{13} \mathrm{C}$ NMR spectrum could be attributed to C-30 for the same $2 \mathrm{D}$ NMR evidence of $1 \mathrm{a}$. The ${ }^{1} \mathrm{H}$ NMR spectrum of $\mathbf{1 b}$ showed two new proton signals at $\delta_{\mathrm{H}} 4.49$ $(\mathrm{d}, 1 \mathrm{H}, J=11.0 \mathrm{~Hz})$ and $3.67(\mathrm{~d}, 1 \mathrm{H}, J=11.0 \mathrm{~Hz}) \mathrm{ppm}$, whereas the DEPT spectrum showed the presence of a new $\mathrm{CH}_{2}$ signal at $\delta_{\mathrm{C}} 65.04 \mathrm{ppm}$, with the disappearance of one methyl group's carbon signals, confirming that $\mathbf{1 b}$ was a monohydroxylated metabolite of 1a. In the HSQC experiment, the new proton signals showed correlations with the new carbon signal at $\delta_{\mathrm{C}}$ 65.04 ppm, and in the HMBC experiment, the new $\mathrm{CH}_{2}$ signals showed long-range (two- and three-bond) ${ }^{1} \mathrm{H}-{ }^{13} \mathrm{C}$ correlations with C-3 and C-4, confirming C-23 or C-24 as the site of hydroxylation. Furthermore, the relative stereochemistry of the hydroxyl group was established as axial based on NOESY data (Fig. 2). The NOESY spectrum of $\mathbf{1 b}$ showed NOE enhancements between the new proton signals at $\delta_{\mathrm{H}} 4.49(\mathrm{~d}, 1 \mathrm{H}, J=11.0 \mathrm{~Hz})$ and $3.67(\mathrm{~d}, 1 \mathrm{H}, J=11.0 \mathrm{~Hz}) \mathrm{ppm}$ with $\delta_{\mathrm{H}} 0.88 \mathrm{ppm}(\mathrm{s}, 3 \mathrm{H}$, $\mathrm{H}-25)$, indicating that the hydroxyl group was substituted at $\mathrm{C}-24$. Based on all the evidence, metabolite $\mathbf{1 b}$ was characterized as 3ß,24-dihydroxy-urs-12-en-28,30-dioic acid, which is a new compound.

S. griseus ATCC 13273 was found to be a potent strain based on the regioselective unactivated $\mathrm{C}-\mathrm{H}$ bond oxidation of PTs, as it conducted the same oxidation reactions to ursolic acid (1) as well as oleanolic acid ${ }^{24}$ on the same reaction sites (the methyl group on C-4 and C-20).

To understand the conversion process of ursolic acid (1) by S. griseus ATCC 13273, we next conducted a time-course analysis of the biotransformation process of 1 (ESI Fig. S21†). Then, we subjected 1a as the substrate, which also resulted in the product of $\mathbf{1 b}$. Therefore, in the biotransformation process, 1a was the initial product of $\mathbf{1}$, and $\mathbf{1 b}$ was the further oxidized product via 1a.

To further explore the biotransformation capability of S. griseus ATCC 13273 to ursane triterpenes and investigate the influence of the hydroxyl substitutions on A and B rings in the reactions, another four ursane-type substrates, 3-oxo ursolic acid (2), corosolic acid (3), asiatic acid (4) and madasiatic acid (5), were screened.

Biotransformation of 3-oxo ursolic acid (2, $150 \mathrm{mg}$ ) with $S$. griseus ATCC 13273 also resulted in two additional polar metabolites 2a (38.5 mg, yield 24.1\%) and 2 b (75.9 mg, yield 45.9\%) (Fig. 3A). Two additional polar metabolites, 3a (46.2 mg, yield $29.0 \%$ ) and $3 \mathbf{b}$ (29.2 mg, yield 15.9\%) (Fig. 3B), were isolated from the biotransformation of corosolic acid (3, $150 \mathrm{mg})$.

Based on the HR-ESI-MS, 1D and 2D NMR data and the reaction types on ursolic acid, compound $2 \mathbf{a}$ was identified as 3-oxo-urs-12-en-28, 30-dioic acid; compound $\mathbf{2 b}$ was identified as 24-hydroxy-3-oxo-urs-12-en-28,30-dioic acid; ${ }^{24}$ compound $\mathbf{3 a}$ was identified as $2 \alpha, 3 \beta$-dihydroxy-urs-12-ene-28,30-dioic acid, and compound $\mathbf{3 b}$ was identified as $2 \alpha, 3 \beta, 24$-trihydroxy-urs-12ene-28,30-dioic acid (the structure elucidation can be seen in the ESI $\dagger$ ).

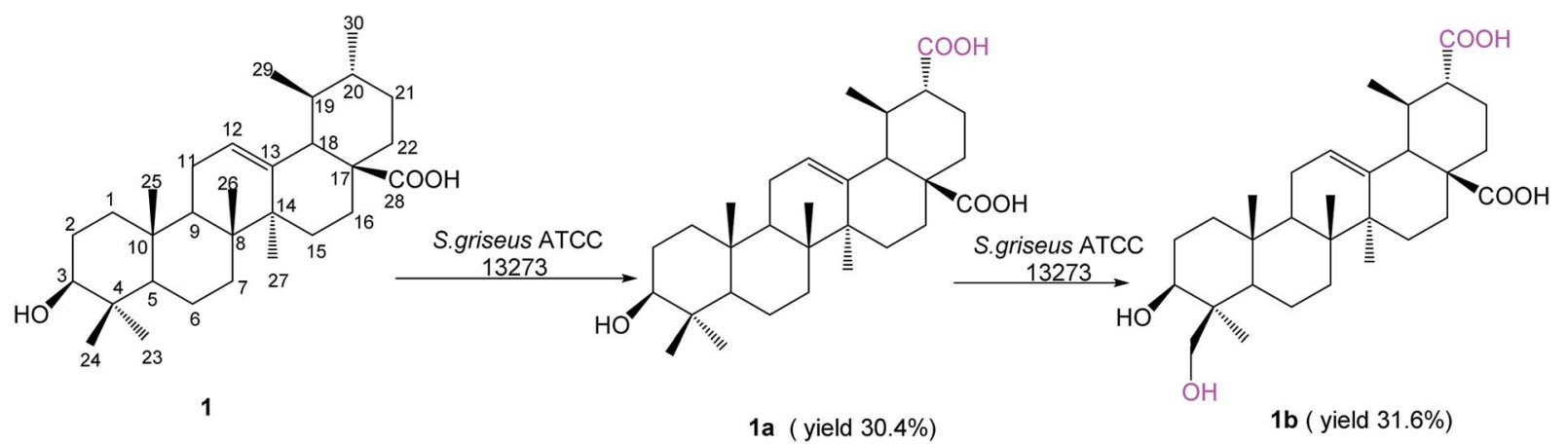

Fig. 1 Biotransformation of ursolic acid (1) by S. griseus ATCC 13273. 

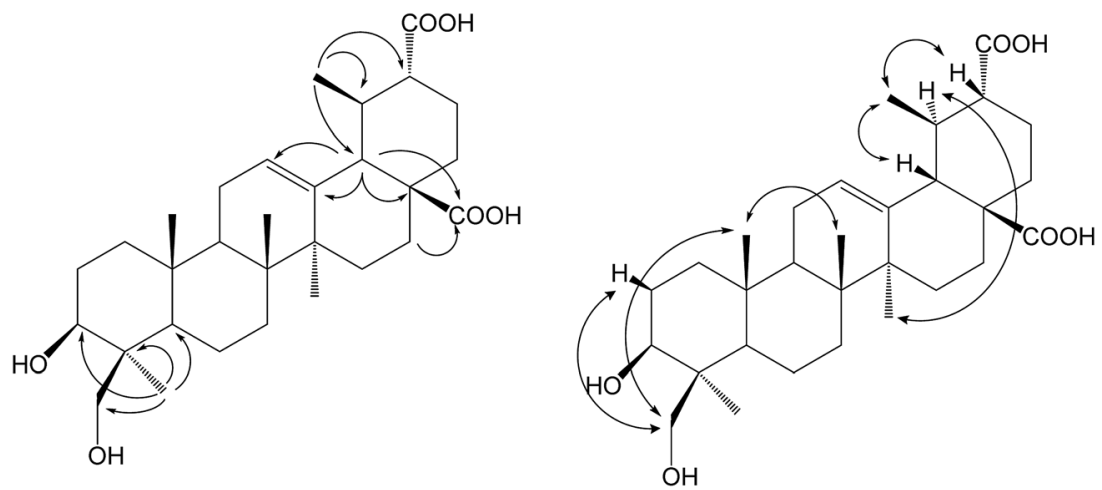

Fig. 2 Key HMBC and NOESY correlations of compound $2 b$

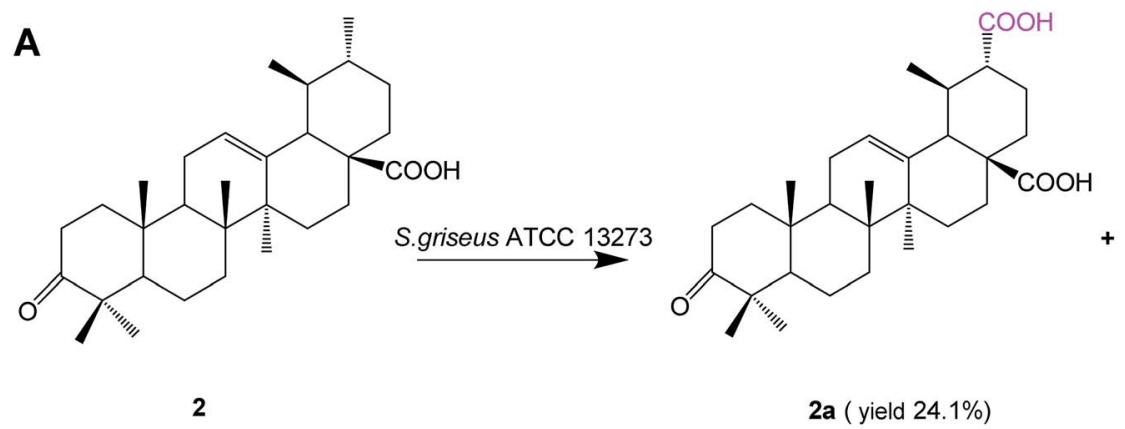<smiles>C[C@H]1[C@@H](C(=O)O)CC[C@]2(C(=O)O)CC[C@]3(C)C(=CCC4[C@@]5(C)CCC(=O)[C@](C)(CO)C5CC[C@]43C)[C@H]12</smiles>

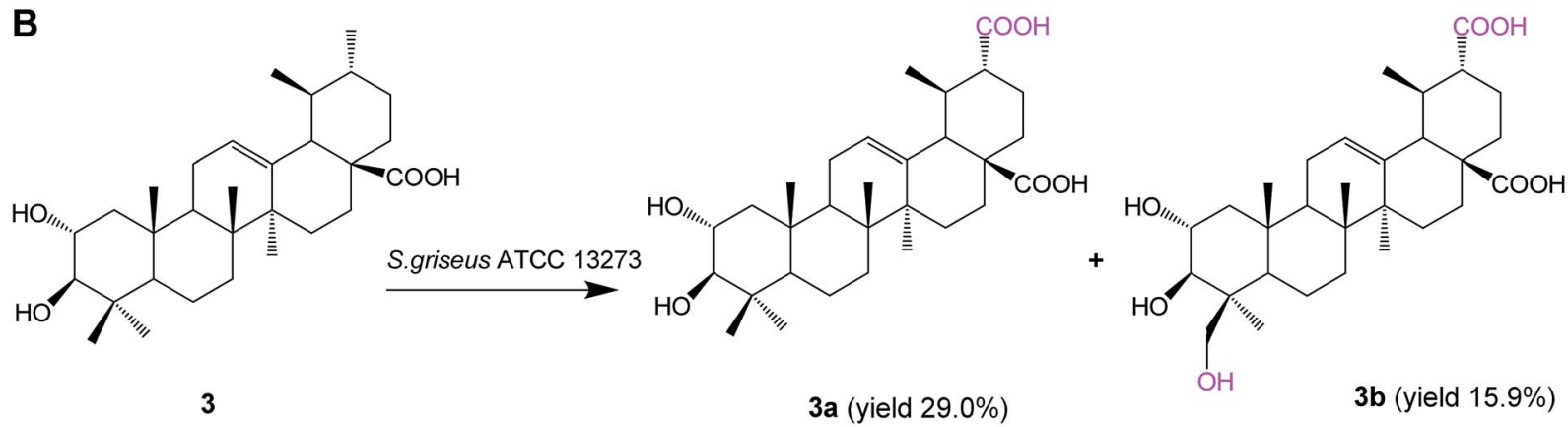

Fig. 3 Biotransformation of 3-oxo ursolic acid (2) and corosolic acid (3) by S. griseus ATCC 13273.

Biotransformation of asiatic acid $(\mathbf{4}, 100 \mathrm{mg})$ with $S$. griseus ATCC 13273 resulted in only one additional polar metabolite, $\mathbf{4 a}$ (52.1 mg, yield 49.1\%) (Fig. 4).

Compound 4a was obtained as a white amorphous powder. The HR-ESI-MS of compound $4 \mathbf{a}$ showed an $[\mathrm{M}-\mathrm{H}]^{-}$ion at $\mathrm{m} / \mathrm{z}$ 517.3164 (calcd for $\mathrm{C}_{30} \mathrm{H}_{45} \mathrm{O}_{7}, 517.3171$ ), which indicated an increment of $30 \mathrm{amu}$ as compared to compound $\mathbf{4}$. Then, $\mathbf{4 a}$ was characterized as $2 \alpha, 3 \beta, 23$-trihydroxy-urs-12-ene-28,30-dioic acid due to its NMR spectral data being identical to those reported in the literature. ${ }^{25}$

Biotransformation of madasiatic acid $(5,100 \mathrm{mg})$ with S. griseus ATCC 13273 resulted in two additional polar metabolites, 5a (12.5 mg, yield $12.1 \%)$ and $\mathbf{5 b}(33.4 \mathrm{mg}$, yield $31.5 \%)$ (Fig. 5).

The HR-ESI-MS of compound 5a showed an $[\mathrm{M}-\mathrm{H}]^{-}$ion at $\mathrm{m} / \mathrm{z} 519.3319$ (calcd for $\mathrm{C}_{30} \mathrm{H}_{47} \mathrm{O}_{7}, 519.3327$ ), indicating a 16 amu mass increase compared to that of compound 5. The ${ }^{1} \mathrm{H}$ NMR spectrum of compound $\mathbf{5 a}$ displayed five characteristic methyl groups in the absence of one splitting methyl signal in the substrate. The DEPT spectrum exhibited a new methylene carbon signal at $\delta_{\mathrm{C}} 65.66 \mathrm{ppm}$, confirming C-30 or C-29 as the site of hydroxylation. The hydroxylation at C-30 was authenticated by the paramagnetic shifts of the neighboring carbons C-20 (from $\delta_{\mathrm{C}} 39.99 \mathrm{ppm}$ of the substrate to $\delta_{\mathrm{C}} 47.97 \mathrm{ppm}$ ), whereas the signals of C-19 and C-21 shifted upfield by 5.52 and $5.41 \mathrm{ppm}$, respectively. The HMBC spectrum exhibited correlations of $\mathrm{H}-30$ with C-19 and C-21, as well as $\mathrm{H}-29$ with C-18, C-19 and C-20, which further confirmed the structure of the compound $5 \mathbf{a}$ as $2 \alpha, 3 \beta, 6 \beta, 23,30$-pentahydroxy-urs-12-ene-28-oic acid.

The molecular formula of $\mathbf{5 b}$ was established as $\mathrm{C}_{30} \mathrm{H}_{46} \mathrm{O}_{8}$ based on HR-ESI-MS, in which a quasimolecular ion was detected at $\mathrm{m} / \mathrm{z} 533.3113[\mathrm{M}-\mathrm{H}]^{-}$(calcd for $\mathrm{C}_{30} \mathrm{H}_{45} \mathrm{O}_{8}$, 

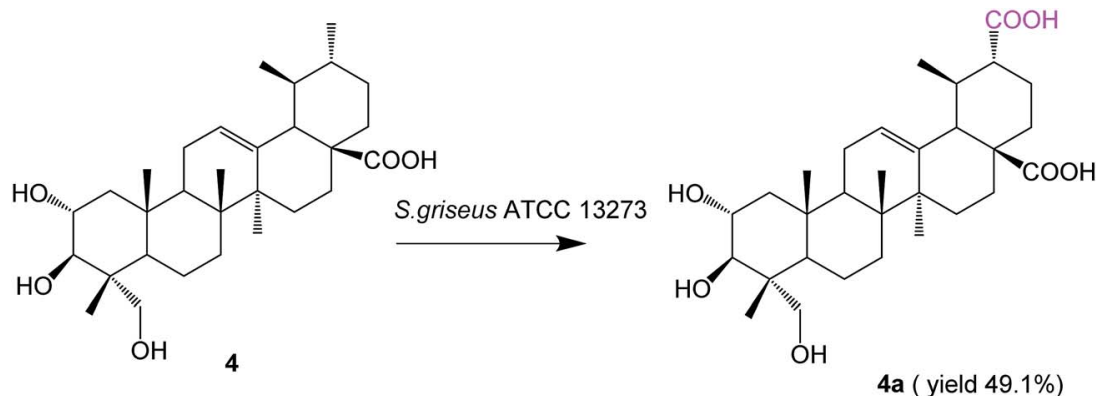

Fig. 4 Biotransformation of asiatic acid (4) by S. griseus ATCC 13273.

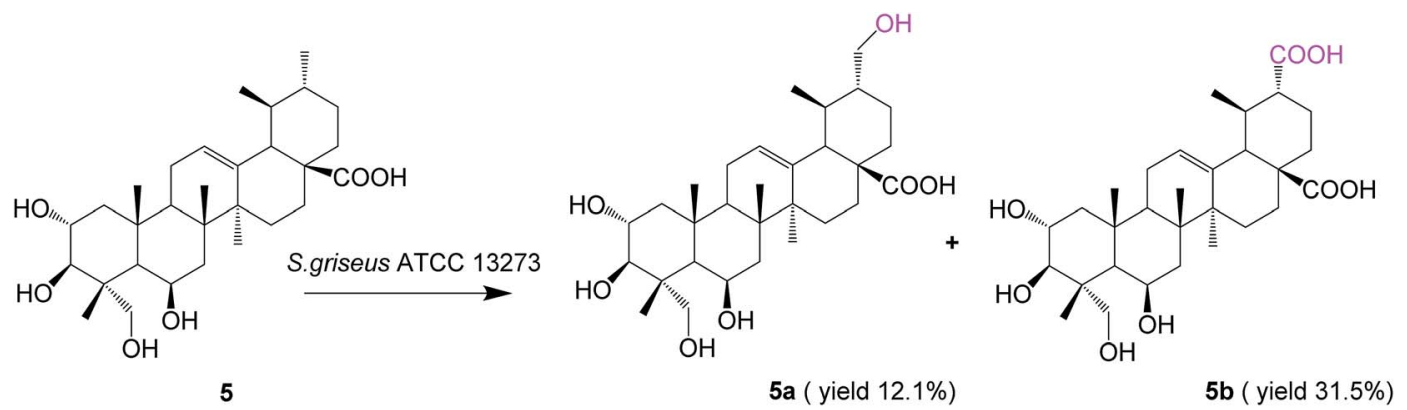

Fig. 5 Biotransformation of madasiatic acid (5) by S. griseus ATCC 13273.

533.3120), indicating a 30 amu mass increase compared to that of compound 5. According to a similar analysis of the NMR spectrum with $\mathbf{3 a}$ and $\mathbf{4 a}$, we judged that the C-30 methyl group of 5 was oxidized to the corresponding carboxyl group. Compound $\mathbf{5 b}$ was identified as $2 \alpha, 3 \beta, 6 \beta, 23$-tetrahydroxy-urs12-ene-28,30-dioic acid, and it is reported for the first time.

It was encouraging to find that $S$. griseus ATCC 13273 could catalyze highly efficient regioselective methyl oxidation at C30 for all of these ursane triterpenes, regardless of the variation of hydroxyl substitutions on A and B rings. The hydroxylation of methyl at C-24 would be shielded when the substrates (compound $\mathbf{4}$ and 5 ) bear the vicinal hydroxymethyl group at C-23. Moreover, the methyl group at C-30 of compounds 1-4 could be deeply oxidized to a carboxyl group rapidly, and no potential intermediates were observed in the HPLC analysis, but to the substrate 5, bearing one hydroxyl substitution at C-6, the hydroxylated intermediate (compound 5a) was isolated. Therefore, we speculated that the hydroxyl substitution at C- 6 or excessive hydroxyl substitutions on $\mathrm{A}$ and $\mathrm{B}$ rings may slow the progress of further oxidation of methyl at C-30. This reaction would also provide a new active-site on the $\mathrm{E}$ rings for further structural modification of PTs. In general, the facile biocatalytic oxidation of the unactivated $\mathrm{C}-\mathrm{H}$ bonds by whole cells illustrates the advantages and properties of microbial transformations very well in a reaction that is difficult to achieve using synthetic chemical methods. ${ }^{26,27}$ Developing green and highly regioselective catalytic methods for the oxidation of unactivated $\mathrm{sp}^{3}$ $\mathrm{C}-\mathrm{H}$ bonds will have widespread applications in synthetic chemistry.
Table 1 In vitro cytotoxicities of the substrates with more than fifty percent inhibition rate in $50 \mu \mathrm{M}$

\begin{tabular}{|c|c|c|c|c|c|c|}
\hline \multirow[b]{3}{*}{ Compounds } & \multicolumn{6}{|c|}{ Inhibition rate $(\%) 72 \mathrm{~h}$} \\
\hline & \multicolumn{3}{|c|}{ HepG-2 } & \multicolumn{3}{|l|}{ MCF-7 } \\
\hline & $50 \mu \mathrm{M}$ & $10 \mu \mathrm{M}$ & $1 \mu \mathrm{M}$ & $50 \mu \mathrm{M}$ & $10 \mu \mathrm{M}$ & $1 \mu \mathrm{M}$ \\
\hline 1 & 60.1 & 5.4 & -7.2 & 78.1 & -32.6 & 5.7 \\
\hline 3 & 94.6 & -7.5 & -4.8 & 83.9 & 6.7 & 5.6 \\
\hline 4 & 91.8 & -3.3 & -0.9 & 70.5 & 23.1 & 5.2 \\
\hline
\end{tabular}

\section{Cytotoxic activities of the compounds}

All compounds were tested for in vitro cytotoxicity. Ursolic acid (1), corosolic acid (3) and asiatic acid (4) showed an inhibitory effect against HepG-2 human hepatoma cancer cells and MCF-7 human breast cancer cells (see Table 1). None of the metabolites showed significant inhibitory activities against these cancer cell lines, which may be due to the toxicity attenuated effect of microbial metabolism on exogenous substrates.

\section{Experimental}

\section{General procedures}

NMR spectra were recorded on a Bruker AV-500 spectrometer in $\mathrm{C}_{5} \mathrm{D}_{5} \mathrm{~N}$ solution with TMS as the internal standard, and chemical shifts were expressed in $\delta$ (parts per million). HR-ESI-MS experiments were performed on an Agilent 6210 ESI-TOF spectrometer. Preparative HPLC was carried out on a SHIMADZU system with an Ultimate ${ }^{\circledR}$ LP-C18 column $(10 \times 250 \mathrm{~mm})$. The 
high performance liquid chromatography (HPLC) analysis was performed on an Agilent 1260 system with an Ultimate ${ }^{\circledR}$ LP-C18 column $(4.6 \times 200 \mathrm{~mm})$ eluent: acetonitrile/water, flow rate: 1.0 mL $\min ^{-1}$, detector: Alltech 3300 ELSD. All of the solvents used for extraction and isolation were of analytical grade. TLC was performed on precoated silica gel $\mathrm{GF}_{254}$ plates. Separation and purification were carried out by column chromatography on silica gel (200-300 mesh). Silica gel was purchased from Qingdao Marine Chemical Group Co., PR China.

\section{Substrates and microorganism}

Ursolic acid (1) and corosolic acid (3) were purchased from Spring\&Autumn Pharmacy Co., Ltd., Nanjing China. 3-Oxo ursolic acid (2) was prepared by the oxidation of 1 with Jones reagent and purified by crystallization in methanol. Asiatic acid (4) and madasiatic acid (5) were isolated from Centella asiatica in our lab. Their structures were characterized by ${ }^{1} \mathrm{H}$ NMR, ${ }^{13} \mathrm{C}$ NMR, and MS spectra (see Table S1 $\dagger$ ).

S. griseus ATCC 13273 was obtained by courtesy of Prof. John P. N. Rosazza of the University of Iowa, USA.

\section{Analytical and preparative scale biotransformation, isolation, and identification of biotransformation products}

Cultures were grown by a two-stage procedure in $50 \mathrm{~mL}$ of soybean meal glucose medium held in $250 \mathrm{~mL}$ culture flasks. The soybean meal glucose medium contained (in $\mathrm{g} \mathrm{L}^{-1}$ ) 20 glucose, 5 yeast extract, 5 soybean meal, $5 \mathrm{NaCl}$, and $5 \mathrm{~K}_{2} \mathrm{HPO}_{4}$ in distilled water and was adjusted to $\mathrm{pH} 7.0$ with $6 \mathrm{~N} \mathrm{HCl}$ before being autoclaved at $121{ }^{\circ} \mathrm{C}$ for $15 \mathrm{~min}$. Cultures were incubated with shaking at $180 \mathrm{rpm}$ at $28{ }^{\circ} \mathrm{C}$. A $10 \%$ inoculum derived from $48 \mathrm{~h}$-old stage I cultures was used to initiate stage II cultures, which were incubated for $24 \mathrm{~h}$ before receiving $10 \mathrm{mg}$ of substrates in $1 \mathrm{~mL}$ of DMSO, and incubations were conducted as before. Substrate controls consisted of sterile medium and substrates incubated under the same conditions but without microorganisms. Cultures were incubated for 3-5 days and extracted with equal volumes of EtOAc. The organic phase was concentrated and spotted on a silica gel TLC plate, which was developed by chloroform/methanol $(10: 1, \mathrm{v} / \mathrm{v})$. The results were visualized by spraying with $\mathrm{H}_{2} \mathrm{SO}_{4}(10 \%$ in ethanol) and heating at $120^{\circ} \mathrm{C}$ for $1-2 \mathrm{~min}$.

Using 24 h-old stage II cultures, the substrate (1-3, $150 \mathrm{mg} ; 4$ and 5, $100 \mathrm{mg}$ ) was distributed evenly among thirty $125 \mathrm{~mL}$ culture flasks. Substrates containing cultures were incubated for 3-5 days and then extracted with equal volumes of EtOAc three times. The organic solvent layer was evaporated to dryness. The crude extracts of substrates 1-5 were subjected to silica gel column chromatography eluted with a solvent system of chloroform/methanol ( $99: 1$ to $90: 10)$ to afford the fractions 1-5, respectively. Fraction 1 was purified by preparative HPLC with acetonitrile : $\mathrm{H}_{2} \mathrm{O}=45: 55,14 \mathrm{~mL} \mathrm{~min}^{-1}$. Metabolites 1a (48.6 mg) and $\mathbf{1 b}(52.1 \mathrm{mg})$ were isolated. Fraction 2 was purified by preparative HPLC with acetonitrile : $\mathrm{H}_{2} \mathrm{O}=55: 45,14$ $\mathrm{mL} \min ^{-1}$. Metabolites 2a (38.5 mg) and 2b (75.9 mg) were isolated. Fraction 3 was purified by preparative HPLC with acetonitrile : $\mathrm{H}_{2} \mathrm{O}=42: 58,14 \mathrm{~mL} \mathrm{~min}^{-1}$. Metabolites 3a (46.2 $\mathrm{mg}$ ) and 3b (29.2 mg) were isolated. Fraction 4 was purified again by silica gel column chromatography eluted with a solvent system of chloroform/methanol (93: 7 to $90: 10$ ) to afford 4 a (52.1 $\mathrm{mg})$. Fraction 5 was purified by preparative HPLC with acetonitrile $: \mathrm{H}_{2} \mathrm{O}=40: 60,14 \mathrm{~mL} \min ^{-1}$. Metabolites 5a (12.5 mg) and $\mathbf{5 b}$ (33.4 mg) were isolated. The structures were identified based on their HR-MS and NMR.

Metabolite 1a. White solid, HR-ESI-MS: $\mathrm{m} / \mathrm{z}$ 485.3260, $[\mathrm{M}-\mathrm{H}]^{-}$(calcd for $\left.\mathrm{C}_{30} \mathrm{H}_{45} \mathrm{O}_{5}, 485.3272\right),{ }^{13} \mathrm{C}$ NMR $(125 \mathrm{MHz}$, pyridine-d5), see Table $\mathrm{S} 2 . \dagger$

Metabolite 1b. White solid, HR-ESI-MS: $\mathrm{m} / \mathrm{z}$ 501.3222, $[\mathrm{M}-\mathrm{H}]^{-}$(calcd for $\left.\mathrm{C}_{30} \mathrm{H}_{45} \mathrm{O}_{6}, 501.3222\right),{ }^{1} \mathrm{H} \mathrm{NMR}(500 \mathrm{MHz}$, pyridine-d5), see Fig. S2. ${ }^{13} \mathrm{C}$ NMR (125 MHz, pyridine-d5), see Table S2. $\dagger$

Metabolite 2a. White solid, HR-ESI-MS: $\mathrm{m} / \mathrm{z}$ 483.3088, $[\mathrm{M}-\mathrm{H}]^{-}$(calcd for $\left.\mathrm{C}_{30} \mathrm{H}_{43} \mathrm{O}_{5}, 483.3115\right),{ }^{13} \mathrm{C}$ NMR $(125 \mathrm{MHz}$, pyridine-d5), see Table S2. $\dagger$

Metabolite 2b. White solid, HR-ESI-MS: $\mathrm{m} / \mathrm{z}$ 499.3049, $[\mathrm{M}-\mathrm{H}]^{-}$(calcd for $\left.\mathrm{C}_{30} \mathrm{H}_{44} \mathrm{O}_{6}, 499.3065\right),{ }^{13} \mathrm{C}$ NMR $(125 \mathrm{MHz}$, pyridine-d5), see Table S2.†

Metabolite 3a. White solid, HR-ESI-MS: $\mathrm{m} / \mathrm{z}$ 501.3215, $[\mathrm{M}-\mathrm{H}]^{-}$(calcd for $\left.\mathrm{C}_{30} \mathrm{H}_{45} \mathrm{O}_{6}, 501.3222\right),{ }^{13} \mathrm{C}$ NMR $(125 \mathrm{MHz}$, pyridine-d5), see Table $\mathrm{S} 2 . \dagger$

Metabolite 3b. White solid, HR-ESI-MS: $\mathrm{m} / \mathrm{z}$ 517.3167, $[\mathrm{M}-\mathrm{H}]^{-}$(calcd for $\left.\mathrm{C}_{30} \mathrm{H}_{45} \mathrm{O}_{7}, 517.3171\right),{ }^{13} \mathrm{C} \mathrm{NMR}(125 \mathrm{MHz}$, pyridine-d5), see Table $\mathrm{S} 2 . \dagger$

Metabolite 4a. White solid, HR-ESI-MS: $m / z$ 517.3164, $[\mathrm{M}-\mathrm{H}]^{-}$(calcd for $\left.\mathrm{C}_{30} \mathrm{H}_{45} \mathrm{O}_{7}, 517.3171\right),{ }^{13} \mathrm{C} \mathrm{NMR}(125 \mathrm{MHz}$, pyridine-d5), see Table S2.†

Metabolite 5a. White solid, HR-ESI-MS: $\mathrm{m} / \mathrm{z}$ 519.3319, $[\mathrm{M}-\mathrm{H}]^{-}$(calcd for $\left.\mathrm{C}_{30} \mathrm{H}_{47} \mathrm{O}_{7}, 519.3327\right),{ }^{13} \mathrm{C}$ NMR $(125 \mathrm{MHz}$, pyridine-d5), see Table $\mathrm{S} 2 . \dagger$

Metabolite 5b. White solid, HR-ESI-MS: $\mathrm{m} / \mathrm{z}$ 533.3113, $[\mathrm{M}-\mathrm{H}]^{-}$(calcd for $\left.\mathrm{C}_{30} \mathrm{H}_{45} \mathrm{O}_{8}, 533.3120\right),{ }^{13} \mathrm{C} \mathrm{NMR}(125 \mathrm{MHz}$, pyridine-d5), see Table S2.†

\section{Time course for the biotransformation of ursolic acid (1)}

Using 24 h-old stage II cultures, $10 \mathrm{mg}$ of substrate 1 in $1 \mathrm{~mL}$ of DMSO was added in each $250 \mathrm{~mL}$ culture flask, and incubations were conducted as before. Substrates containing cultures were incubated for $0,14,24,36,48$ and $72 \mathrm{~h}$, and extracted with equal volumes of EtOAc. The compound contents in the extract were measured by HPLC-ELSD analysis.

\section{Cytotoxicity assay}

Two cancer cell lines, HepG2 and MCF-7, were purchased from Peking Union Medical College (PUMC) Cell Bank (Beijing, China). All cells were maintained in DMEM medium supplemented with $10 \%$ fetal bovine serum. The culture was maintained at $37{ }^{\circ} \mathrm{C}, 5 \% \mathrm{CO}_{2}$, and grown in 96-well microtiter plates for the assay. All media were supplemented with $100 \mathrm{U} \mathrm{mL}^{-1}$ penicillin and $100 \mu \mathrm{g} \mathrm{mL}{ }^{-1}$ streptomycin. The cytotoxic activity in vitro was measured using the MTT assay. The MTT solution (10.0 mL per well) was added in culture media after cells were treated with various concentrations of compounds for $72 \mathrm{~h}$, and cells were incubated for a further $4 \mathrm{~h}$ at $37^{\circ} \mathrm{C}$. The purple 
formazan crystals were dissolved in $100 \mathrm{~mL}$ DMSO. After $10 \mathrm{~min}$, the plates were read on an automated microplate spectrophotometer (Bio-Tek Instruments, Winooski, VT) at $570 \mathrm{~nm}$ and $650 \mathrm{~nm}$. Assays were performed in triplicate on three independent experiments. In all of these experiments, three replicate wells were used to determine each point.

\section{Conclusions}

In conclusion, S. griseus ATCC 13273 showed highly efficient site-selective methyl oxidizing capacity (especially at C-30) over all five substrates of ursane triterpenes, resulting in eight additional unreported metabolites. Moreover, the site-selective oxidation of PTs obtained is particularly valuable for the fact that it provided the new active-site with the ability to access a greater number and larger variety of further derivatives. The wild microbe with such a specific site-selectivity and high conversion rate to multiple substrates is even more remarkable and uncommon. The whole genome of S. griseus 13273 in our lab has been sequenced. Future efforts will focus on the identification, cloning and heterologous expression of cytochrome P450 genes for the discovery of new biocatalysts for the specific oxidation of unactivated $\mathrm{C}-\mathrm{H}$ bonds.

\section{Acknowledgements}

This study was supported by the National Nature Science Foundation of China (NSFC No. 21302052) and the "Program for New Century Excellent Talents in University" awarded to Prof. Jian Zhang. We also acknowledge the ' 111 Project' from the Ministry of Education of China, and the Fundamental Research Funds for Central Universities(JKZ2011017), and the scientific and innovation research of college graduate in Jiangsu province (CXLX11_0788).

\section{References}

1 F. J. Reyeszurita, M. Medinao'Donnell, R. M. Ferrermartín, E. E. Rufinopalomares, S. Martinfonseca, F. Rivas, A. Martinez, A. Garciagranados, A. Pérezjiménez and L. Garcíasalguero, RSC Adv., 2016, 6, 93590-93601.

2 K. Reen-Yen, Q. Keduo, S. L. Morris-Natschke and L. KuoHsiung, Nat. Prod. Rep., 2009, 26, 1321-1344.

3 H. Sheng and H. Sun, Nat. Prod. Rep., 2011, 42, 543-593.

4 D. P. Gossan, A. A. Magid, P. A. Yao-Kouassi, J. Josse, S. C. Gangloff, H. Morjani and L. VoutquenneNazabadioko, Fitoterapia, 2016, 110, 89-95.
5 M. G. Ponnapalli, S. Sukki, S. C. V. A. R. Annam, M. Ankireddy, H. Tirunagari, V. R. Tuniki and V. V. P. Bobbili, ChemInform, 2015, 46, 1570-1574.

6 R. Azerad, Fitoterapia, 2016, 114, 168-187.

7 X. Wen, H. Sun, J. Liu, K. Cheng, P. Zhang, L. Zhang, J. Hao, L. Zhang, P. Ni and S. E. Zographos, J. Med. Chem., 2008, 51, 3540-3554.

8 F. Yu, Q. Wang, Z. Zhang, Y. Peng, Y. Qiu, Y. Shi, Y. Zheng, S. Xiao, H. Wang and X. Huang, J. Med. Chem., 2013, 56, 4300-4319.

9 P. Y. Gao, RSC Adv., 2015, 6, 2431-2435.

10 E. M. F. Khusnutdinova, N. I. Medvedeva, D. V. Kazakov, O. S. Kukovinets, A. N. Lobov, K. Y. Suponitsky and O. B. Kazakova, Tetrahedron Lett., 2015, 57, 148-151.

11 B. A. Dar, A. M. Lone, W. A. Shah and M. A. Qurishi, Eur. J. Med. Chem., 2016, 111, 26-32.

12 L. Fu and G. W. Gribble, Org. Lett., 2013, 15, 1622-1625.

13 T. Gensch, M. N. Hopkinson, F. Glorius and J. WencelDelord, Chem. Soc. Rev., 2016, 45, 2900-2936.

14 O. V. Nesterova, M. N. Kopylovich and D. S. Nesterov, RSC Adv., 2016, 6, 93756-93767.

15 G. Y. Ruan, Z. H. Qi, Y. Zhang, W. Liu and Y. Wang, RSC Adv., 2016, 6, 35855-35858.

16 A. T. Nelson, A. M. Camelio, K. R. Claussen, J. Cho, L. Tremmel, J. Digiovanni and D. Siegel, Bioorg. Med. Chem. Lett., 2015, 25, 4342.

17 L. Fu and G. W. Gribble, Org. Lett., 2013, 15, 1622.

18 M. Schrewe, M. K. Julsing, B. Bühler and A. Schmid, Chem. Soc. Rev., 2013, 42, 6346-6377.

19 H. L. T. Syed Adnan Ali Shah, S. Sultan, M. A. B. M. Faridz, M. A. B. M. Shah, S. Nurfazilah and M. Hussain, Int. J. Mol. Sci., 2014, 15, 12027-12060.

20 D. Zhou, N. Li, Y. Zhang, C. Yan, K. Jiao, Y. Sun, H. Ni, B. Lin and Y. Hou, RSC Adv., 2016, 6, 97302-97312.

21 F. Xu, K. Liao, Y. Liu, Z. Zhang, D. Guo, Z. Su and B. Liu, Fitoterapia, 2016, 109, 201-205.

22 J. L. Tian, Y. Chen, Y. X. Wang, X. Huang, X. Sun, K. C. Liu and S. J. Song, RSC Adv., 2016, 6, 112712-112720.

23 L.-W. Qian, J. Zhang, J.-H. Liu and B.-Y. Yu, Tetrahedron Lett., 2009, 50, 2193-2195.

24 Y. Y. Zhu, L. W. Qian, J. Zhang, J. H. Liu and B. Y. Yu, Tetrahedron, 2011, 67, 4206-4211.

25 F. F. Guo, X. Feng, Z. Y. Chu, D. P. Li, L. Zhang and Z. S. Zhang, J. Asian Nat. Prod. Res., 2013, 15, 15-21.

26 M. J. Acerson, B. S. Bingham, C. A. Allred and M. B. Andrus, Tetrahedron Lett., 2015, 56, 3277-3280.

27 C. Hui and J. Xu, Tetrahedron Lett., 2016, 57, 2692-2696. 